\title{
Poland: Polish Education Reforms and Evidence from International Assessments
}

\author{
Maciej Jakubowski
}

\begin{abstract}
Over the last two decades, the Polish education system has been reformed several times, with the comprehensive structural reform in 1999, curriculum and evaluation reform in 2007, and early education reform introduced gradually until 2014. Student outcomes, as documented by PISA, but also other international assessments, largely improved over the last 20 years. Poland moved from below the OECD average to a group of top-performing countries in Europe. This chapter describes the reforms and research on their effects. It also discusses how it was possible to find political support for the reversal of changes that seemed to be highly successful. It provides three lessons from the Polish experience. First, the evidence should be widely disseminated among all stakeholders to sustain reforms. Second, the sole reliance on international studies is not sufficient. Additional investment into secondary analyses and national studies is necessary to develop evidence for better-informed political discussions. Third, some positive changes are more difficult to reverse. In Poland, increased school autonomy, but also external examinations, broader access to preschool and higher education, are among the changes that the new government could not alter.
\end{abstract}

\section{Expansion of General Education as the Overarching Idea of the Polish School Reforms}

This paper discusses how Polish education has changed over the last 20 years and the evidence on reform outcomes, mainly from the PISA assessment, but also from other international and national research. It also addresses the complex relations between research evidence, policymaking, and politics, providing some insights into recent changes in the Polish education system.

With the collapse of the communist system in 1989, Poland experienced a rapid transition from a centrally-planned to a market economy in the 1990s. The so-called

\footnotetext{
M. Jakubowski ( $\square)$

Faculty of Economic Sciences, University of Warsaw, Warsaw, Poland

e-mail: mjakubowski@uw.edu.pl
} 
shock therapy introduced in 1990 quickly transformed Poland into one of the fastestgrowing economies in Europe. This rapid transition of the Polish economy was accompanied by a successful transition to parliamentary democracy. The first changes introduced in education focused on cleansing the textbooks and curricula of the political content inherited from communist times. Although the system was decentralized very early, still the key decisions remained with the Ministry of Education and central institutions. Only the responsibility for preschool education was transferred, almost entirely, to the newly established local governments-but the results were unsatisfactory due to insufficient resources (Jakubowski and Topińska 2009). It took a whole decade to prepare for more in-depth structural reforms of the Polish education system.

The education reforms started in 1999 and were continued until recently. The goals of the 1999 reform were to improve the quality of education and to increase educational opportunities for all students, but politically it was supported by those who wanted to break once and for all with an educational system inherited from the communist times. The reform also responded to the changing economy and increasing demand for skilled workers, which was driven by the fast-growing economy and increased integration with Western European markets.

For politically minded commentators, the education reforms in Poland were inconsistent and did not lead to substantial improvements. However, more careful analyses of policy objectives and outcomes suggest the opposite. Despite differences in opinion and the usual politics, the education reforms had one overarching idea behind them: to expand comprehensive education so as to provide learning opportunities for all students. The structural reform of 1999 replaced 8 years of primary school with 9 years of comprehensive education in primary and lower secondary schools. The curricular reform of 2008 introduced a new requirement for all vocational schools to cover at least a one-year equivalent of the core subjects taught in academic schools. In a way, it also completed the reforms begun in 1999 through the introduction of a consistent curriculum emphasising key competencies from preschool up to the end of upper secondary education. Finally, the reform of early education started in 2009 and was continued until 2015. It introduced compulsory education for 5-year-olds and extended the right to a preschool education to 3- and 4-year-olds. Overall, the reforms expanded the length of compulsory comprehensive education from 8 to 10 years. In 2015, general education started at the age of 3 and continued until the age of 16 . Unfortunately, in 2016 these reforms were in large part reversed and now the period of general education is again shorter.

International assessments document large improvements in student outcomes over the last 20 years. In PISA, Poland has improved its performance from below the OECD average level to above-average performance. The latest results from TIMSS and PIRLS also show improved outcomes in primary education. Finally, the PIAAC assessments of adults show that only the youngest cohorts perform at or above the OECD average. In Europe, Poland is currently among the top performers in international assessment rankings; however, as we will discuss in this paper, this evidence has not been sufficient to convince those who dislike the changes introduced over the last 20 years. 


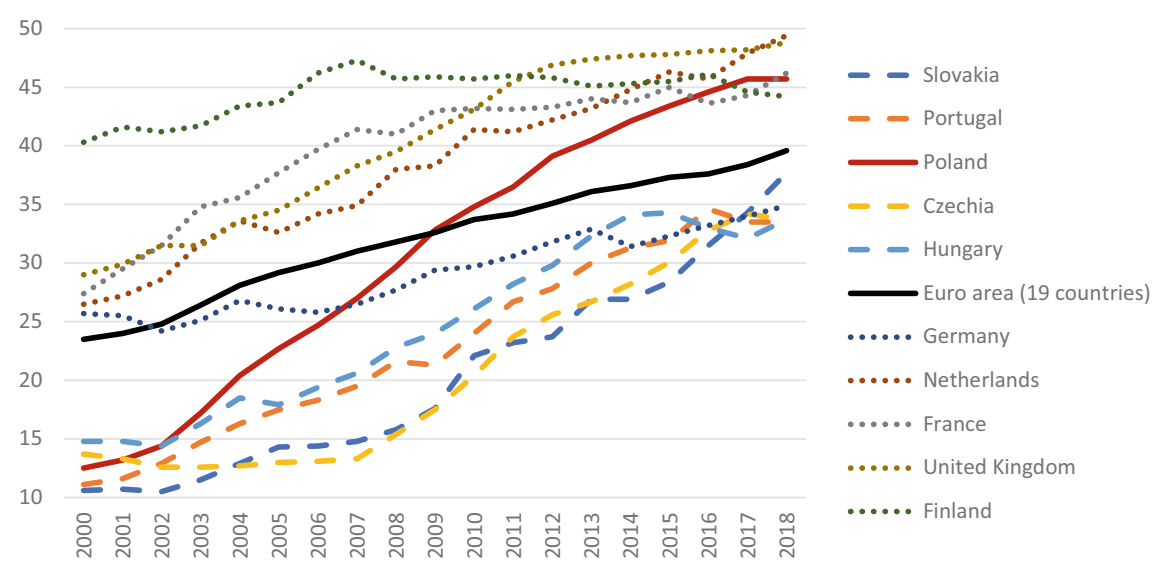

Fig. 1 Tertiary educational attainment-the percentage of the population aged 30-34. Source Eurostat, indicator SDG_04_20

Most importantly, the reforms reached the goals that were set in the 1990s, when they were planned in response to rapid structural changes of the economy and society. Many more students now go to general education upper secondary schools or generalvocational schools, which also provide access to higher education. Fewer go into basic vocational education or stop there without continuing on to higher secondary or tertiary degrees. In 1990, more than one-third of students went into basic vocational education. Now the figure is less than $10 \%$.

The goal of the reforms was to encourage as many students as possible to continue education and to open a way to tertiary education for them. This was entirely successful. Figure 1 compares tertiary education attainment across selected European Union countries. In 2000, only $12.5 \%$ of Polish 30-34-year-olds benefited from having a tertiary degree. This was similar to the proportion of young people finishing tertiary education in other Eastern European countries (e.g., Slovakia, Czechia, Hungary) or to Portugal. However, tertiary attainment was two times higher in EU countries like the Netherlands, France, the UK, or Germany, and around 40\% in Finland. Between 2000 and 2018, Poland experienced the largest increase across the $\mathrm{EU}$ in the proportion of young people obtaining a tertiary diploma (by 33 percentage points).

While there exists a widespread notion that an expansion of tertiary education is associated with a lowering of its quality, the market premium for a tertiary education diploma in Poland is comparable to the average across the EU or OECD countries. The rapid increase in the supply of people with tertiary degrees decreased the wage premium and increased the variability in salaries (see Gajderowicz et al. 2012), but the market valuation of these diplomas is still high. According to the OECD data, in Poland and across the OECD countries, earnings of 25-to-64-year-old adults with tertiary education are around 1.5 times higher compared to those with an upper secondary education (2017 data; Education at a Glance 2019, Table A4.1, OECD). 
Young adults with tertiary degrees are also less affected by economic shocks like the crisis in 2009 and have much higher employment rates.

The direction for the reform of the Polish education system that was set in 1999 is not continued by the current government, which in 2016 reversed the reform that extended comprehensive education, while it promotes vocational education and limits its support for preschool education. This paper discusses evidence from international assessments on how this affected school reforms, but also the fact that the evidence from international and national studies was not sufficient to stop the reversal of the reforms.

\section{PISA as a Necessary but not Sufficient Tool for Policy Evaluation in Poland}

Before the first PISA study was conducted in 2000, there was not a single standardized assessment conducted in Poland that measured student knowledge and skills. The national examinations and university entrance exams were not standardized. The exam at the end of secondary education has the same set of questions for all students, but the results were evaluated differently in each school. Entrance exams for higher education varied between institutions and even between departments of the same university. The only international assessment in which Poland participated was IALS, in 1996, which documented the low level of adult skills in Poland at that time. That was not surprising considering that our society and economy were still in the process of transformation away from the communist system, in which access to higher education was limited, and the economy relied in large part on manufacturing and manual labour.

The results of PISA 2000 were not a surprise as most people expected to see a lower performance of students as compared with much more developed OECD countries. These results showed a dramatically low level of reading skills among students of basic vocational schools, with around $80 \%$ of them scoring below the basic proficiency level in PISA (Level 2). The results for academic upper secondary schools were much higher. This between-school variance, i.e., achievement differences between schools, was one of the highest across the OECD countries and similar to the results for Germany.

The PISA study became the main evaluation tool for the 1999 reform. This was the only standardized assessment providing comparative data at that time. Also, the implementation of PISA coincided with the implementation of the reform. Polish students tested in PISA 2000 were from the last cohort in the old structure of the school system. These students were still in unreformed upper secondary schools and had received only eight years of comprehensive education. The students tested in PISA 2003 were the first cohort that would go through a full three years of education at the newly established lower secondary schools, so this was the first cohort that 
could benefit from the educational reforms. Thus, the comparison between PISA 2000 and PISA 2003 was the main evaluation tool for the 1999 reform.

Similarly, the extensive curriculum changes and introduction of school evaluation systems coincided with PISA studies between 2009 and 2012. Students tested in PISA 2009 were still following the old curriculum, while those tested in 2012 benefited from the new curriculum for the last years of their education prior to the test. School evaluations were also launched around that time. In the future, PISA will be used to evaluate the last changes, which reversed the 1999 structural reform. The latest PISA 2018 covered one of the last cohorts of students who followed nine years of comprehensive education and who studied in the lower secondary schools, which have now been liquidated. In PISA 2021, we will see what the results are of Polish students who have been through the new-old system with a shorter comprehensive education.

Although PISA is the only international assessment in Poland that is conducted repeatedly since 2000 , the other international assessments provide helpful insights into the school system. PIRLS and TIMSS assessed 4th-grade students in 2016 and 2015, respectively (PIRLS was also conducted in 2011 in Poland, but for 3rd graders only). Both showed good results in reading, mathematics, and science, placing Polish students among the top performers in Europe. At the same time, the additional results confirmed other, less positive findings of student attitudes towards school and a sense of belonging. PIAAC, the only international study of adult literacy, showed that the youngest cohort tested in 2011 was the only one that performed at or above the average for the European Union. Also, in this study, the results for numeracy (mathematics) were lower than for literacy (reading). The PIAAC results suggested that only some students of higher education institutions were able to improve their skills after school. Differently than in other countries, the relative performance of adults started to diminish at a younger age, suggesting that the key competencies measured in PIAAC were not sufficiently developed after the completion of schooling (see Rynko 2013).

Figure 2 shows how the international assessments could be used to evaluate learning outcomes for student cohorts, which did or did not benefit from different education reforms. Obviously, the outcomes of international assessments only showed the association between student performance and reforms. Also, the reforms were quite complex, and it is difficult to disentangle various policies to show how they affected students. Finally, in a fast-changing economy and society like the Polish one over the last 20 years, there are numerous factors that could also influence student achievement. In the next section we will discuss how data from international assessments can be used to evaluate some reforms, especially those of 1999 . We will also discuss how other sources of information, e.g., labour market data, can be used to complement these analyses and give insights into causal relations between policies and outcomes.

The collective evidence from large-scale international assessments demonstrates substantial improvements in student outcomes since 2000 and the implementation of the major 1999 reform. In the next section, we will review research using PISA, but also labour market data, using econometric methods for estimating the causal impact 


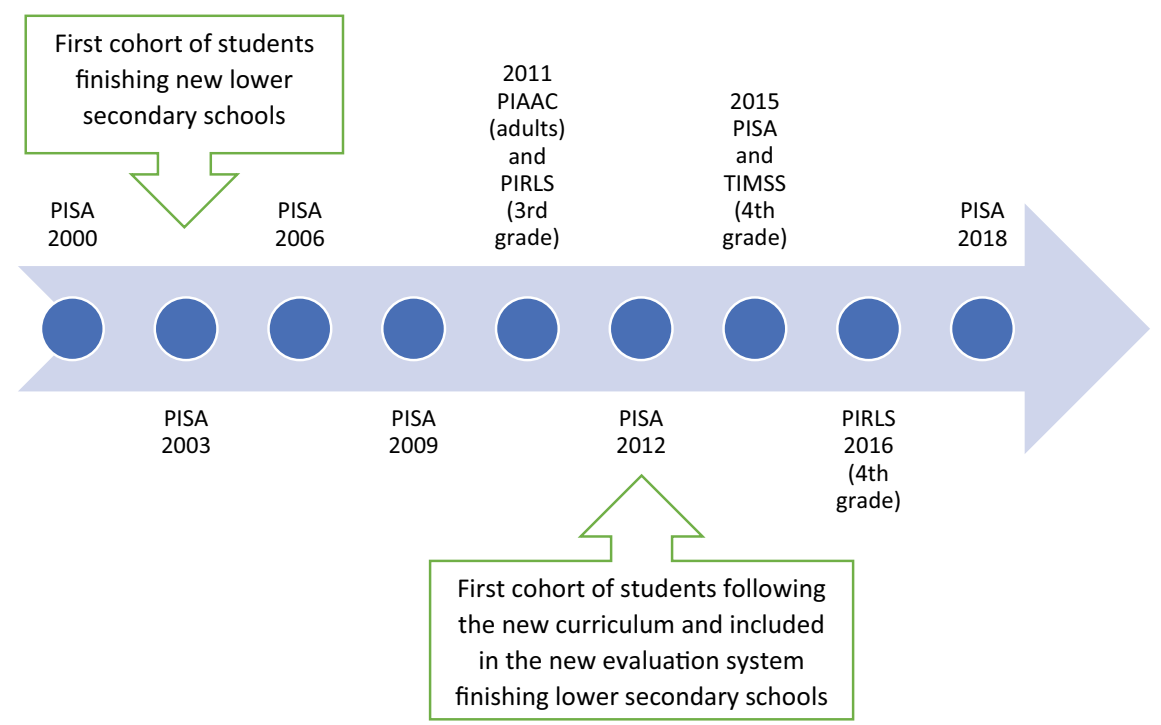

Fig. 2 Key international assessments and major reforms of the Polish school system

of policy changes. Overall, this research provides evidence that the 1999 reform had a sustainable impact on student achievement and later life.

The 1999 reform was planned using examples from other countries and the general notion that comprehensive education is of growing importance in modern economies. At that time, Polish experts and policymakers recognized these needs but were also politically motivated to break with the old system. The reform was implemented alongside other large reforms of the health system, pensions, and local administration. The education reform was implemented rapidly, without the agreement of the trade unions. This left many people with the impression that the reform was not wellprepared and had not been sufficiently discussed with key stakeholders. This might be a reason for the growth in the negative view of the old system that resulted in popular support for reversing the reforms in 2016.

The next large education reforms after 1999 were implemented between 2008 and 2009 and were also largely motivated by experience with international assessments and the opening of discussions about modernizing curricula and teaching methods. Part of the ministerial team that prepared the new curriculum reform took part in the implementation of PISA in Poland. The new curricula focused on expected learning outcomes rather than on the detailed description of what subject content teachers should cover. They also introduced cross-subject topics, emphasized applications, and left to teacher decisions about how some topics should be arranged over time. These changes also emphasized teacher autonomy, leaving more room for teachers to develop individual teaching programs and the use of various materials. The reform of school evaluation was not driven by international assessments, but the team implementing this reform used examples from other countries to build a national evaluation 
framework and to plan the implementation of the school evaluation system. Finally, the reform of early education was driven by international comparisons showing that the simple fact that Polish students began school later and that too few children, especially in rural areas, participated in preschool education. Overall, the reforms were largely driven by international comparisons and expertise.

The knowledge of international assessment results and reliance on international expertise was, however, limited to a group of experts and researchers closely connected to the Ministry of Education (see Bialecki et al. 2017). The popular view of the reforms was driven by sentiment and politics in a way that is now common across different countries and in different policy areas. Opinion polls showed that new lower secondary schools were not very popular among older people and among those with lower education degrees. Among the young people who actually finished these schools, the opinion was more balanced, with a majority opting for keeping them. The lower secondary schools were blamed for behaviour problems and the "theory" of the negative impact of putting teenagers in separate schools became popular, despite the lack of any evidence to support it. In fact, international and national surveys showed that behaviour issues were not that common in these schools and did not increase after their implementation. The evidence on learning outcomes, student opinions, and surveys of behaviour problems had, however, limited impact on popular opinion. This opened up the political possibility of changing the system again, despite the overwhelming evidence but in line with popular sentiments and opinions.

We will now review the evidence used to evaluate the Polish reforms before discussing how it was possible to reverse the reforms despite the clear evidence of their success.

\section{Polish Education Reforms and Evidence on Their Outcomes}

\subsection{PISA Results for Poland}

The average performance of Polish students in PISA has improved since 2000 by more than 30 points in reading, which is one of the largest improvements across the OECD countries. Poland is the only country that has improved its performance to a level close to the best performers in Europe. Most other countries that have substantially improved their performance, e.g., Chile, started from a relatively low level and are still below the OECD average. From the national perspective, improvement in mathematics is especially significant as, until recently, international assessments like PISA and PIAAC demonstrated relatively lower numeracy skills when compared to literacy. Since 2003, mathematics performance has improved in Poland by around 25 points, and now the results in all subjects are similar. 
Changes in the average PISA performance of Polish students are shown in Fig. 3, which documents the progress in all three domains measured in PISA: reading, mathematics, and science. It compares average performance in Poland to the current OECD average, which is slightly below 490 points (487 points in reading, 489 in mathematics, and 489 in science). The results are compared with the first assessment from which reliable trends can be established. Reading has been compared since 2000, but mathematics since 2003 and science since 2006. The results in mathematics and science in 2000 were similar to those for reading, but the assessment frameworks have changed, and the test scores are not directly comparable.

PISA 2018 data provide a unique opportunity to compare reading achievement across seven editions of the PISA survey and between 2000 and 2018. The most reliable comparisons are between 2000 and 2009 and 2009 and 2018. In every edition, PISA measures one domain in a more detailed way, meaning that all students answer questions in that domain and that it is covered by a large number of test questions (more than 100). Reading was the main domain in 2000, 2009, and 2018. Thus, it is possible for the first time in PISA to compare achievement changes across two longer periods. It should be taken into account, however, that the reading assessment framework has slightly changed and that assessments in 2000 and 2009 were conducted on paper, while the 2018 assessment was computer-based (see OECD 2019 for details on the assessment framework and the reliability of the measurement of changes over time).

Poland was one of a few countries that made significant progress in learning outcomes between 2000 and 2018. Moreover, when looking at the low-achieving students, Poland experienced the most substantial improvement across the OECD countries. Figure 4 shows that across the OECD countries, the performance of lowachieving students declined between 2000 and 2018 by around 10 points. Most of this

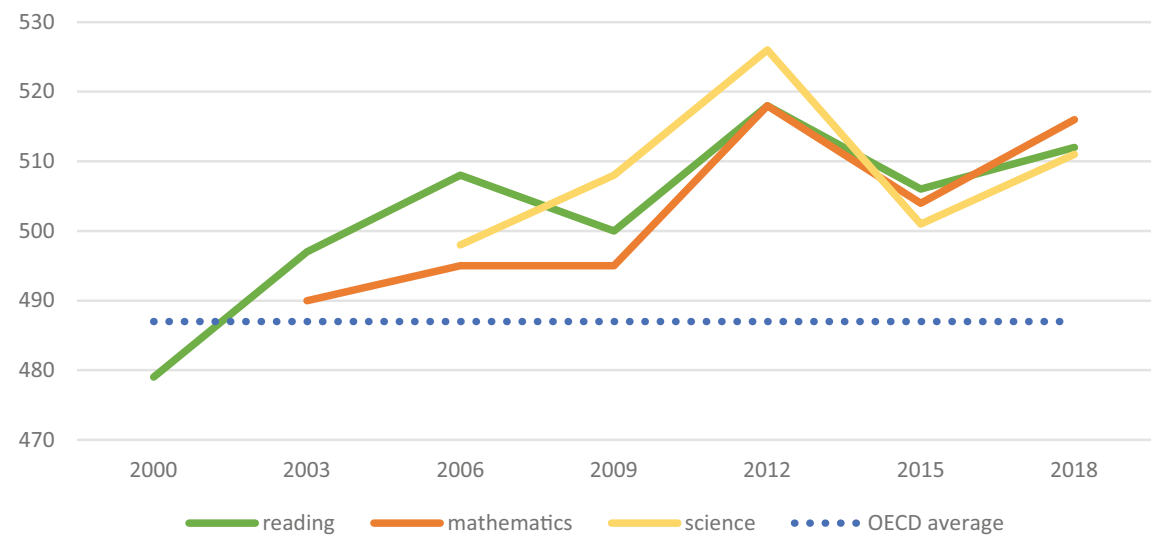

Fig. 3 Achievement trends in PISA average performance in Poland. Source OECD 2019 


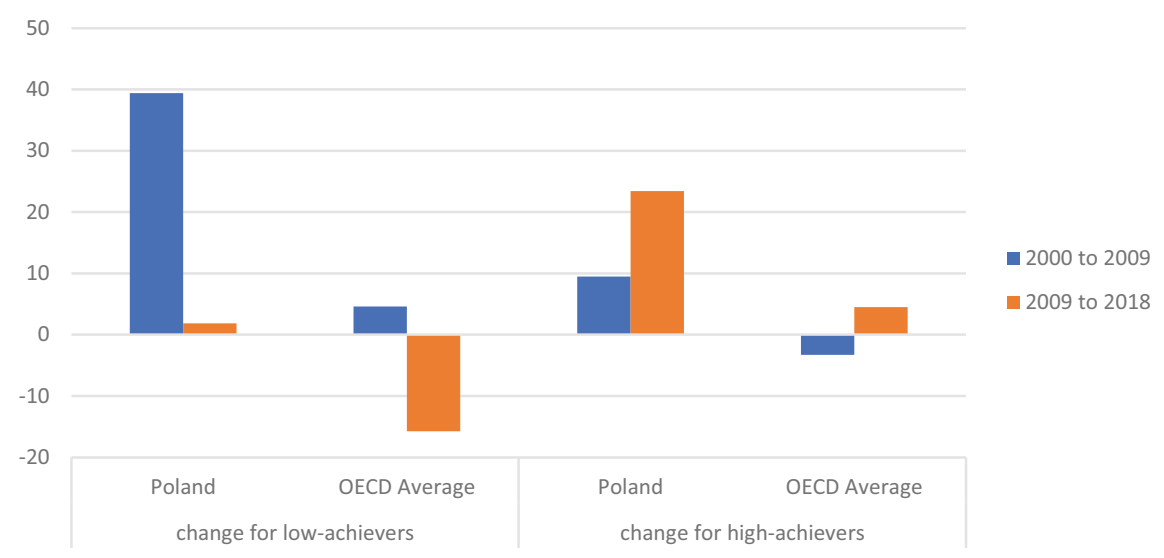

Fig. 4 Changes in reading performance for low- and high-achieving students in Poland and across the OECD countries. Source Table I.B1.13, OECD 2019. Performance of low- and high-achieving students is measured as the 10th and 90th percentile of the performance distribution, respectively

decline was between 2009 and 2018. In Poland, the opposite happened. The performance of low-achievers improved by more than 40 points, and most of the improvement occurred between 2000 and 2009, while there was no change in performance between 2009 and 2018.

The performance of the high-achieving students also improved in Poland, but mostly between 2009 and 2018. Figure 4 shows that across the OECD countries, the performance of high-achievers did not change between 2000 and 2018. A small decline between 2000 and 2009 was counterbalanced by a modest improvement between 2009 and 2018, and the overall change is insignificant. In Poland, the performance of high-achievers improved by 9 points between 2000 and 2009, which was followed by a 23-point increase between 2009 and 2018.

To sum up, the key findings from PISA regarding performance trends in Poland are:

- An overall large improvement of the average performance of Polish students in reading, but also in mathematics;

- A large improvement among low-achievers between 2000 and 2009 (in fact mostly between 2000 and 2003);

- A small improvement between 2000 and 2009 among high-achievers, followed by a large improvement between 2009 and 2018 .

These results should be seen from the perspective of the overall decline in the performance of low-achieving and average students across the OECD countries and stable results for the high-achieving students. We will now discuss the details of the Polish reforms and how evidence from PISA can be used to evaluate them. 


\subsection{The 1999 School Reform and Evidence on Student Outcomes}

The foundations for a modern, effective school system were established by the 1999 reform, which revolutionized the situation in Poland. It not only modified the structure of schools but also increased school and teacher autonomy, freed-up the textbook market, introduced standardized national exams, changed the professional development scheme for teachers, introduced a new financing system that allocated funds according to the per-pupil formula, further decentralized the system and initiated changes in curriculum.

The 1999 school reform had three primary goals:

(a) To improve teaching quality

(b) To increase educational opportunities

(c) To improve efficiency.

The reforms achieved all these goals in the ways anticipated by their authors. Teaching quality was improved, mainly through the introduction of a core curriculum and increased teacher autonomy. Transparency and efficiency of education spending as improved through a formula-based system of resource distribution. The establishment of new, better-equipped, lower secondary schools in rural areas narrowed performance differences between schools. Finally, the reform improved access to tertiary education, and the number of higher education students started to increase rapidly.

The most revolutionary change was related to the restructuring of the school system. The eight-year basic primary education was limited to six years, followed by three years of comprehensive lower secondary education. The selection between different educational programmes was thus postponed by one year, to the age of 16 . In this new system, all students followed the same curriculum for 9 instead of 8 years. Upper secondary education was shortened by one year. As before the reforms, only the basic vocational school does not provide direct access to higher education.

Figure 5 compares the system before and after the 1999 reform, in a transition period from 2008 to 2015 (showing the targeted system at the end of the changes), and after 2016 with most changes reversed. The system introduced after 1999 extended the period of comprehensive education by one year and later introduced a compulsory "zero class" for six-year-olds. Thus, before 2008 it had already added two additional years of compulsory education with the common curriculum. Furthermore, the 2008 reform made it obligatory for basic vocational schools to cover one year of the common curriculum, adding one additional year of general education. Later, compulsory education for five years olds was introduced, and the school starting age was lowered to six. Finally, the government introduced new regulations that guaranteed places in preschool education for 3- and 4-year-olds. Since 2016, the lower secondary schools have been abolished, the upper secondary school curriculum has changed, and compulsory preschool for 5-year-olds has also been abolished. 


\begin{tabular}{|c|c|c|c|c|c|c|c|c|c|c|c|c|}
\hline Age & $3-4$ & 5 & 6 & 7 & 8 & 9 & 10 & 11 & 12 & 13 & 14 & 15 \\
\hline Before 1999 & \multirow{2}{*}{\multicolumn{2}{|c|}{$\begin{array}{l}\text { Voluntary } \\
\text { preschool with no } \\
\text { government } \\
\text { guarantees }\end{array}$}} & "0" & \multicolumn{8}{|c|}{ Primary } & \\
\hline After 1999 & & & "0" & \multicolumn{6}{|c|}{ Primary } & \multicolumn{3}{|c|}{ Lower secondary } \\
\hline $\begin{array}{c}\text { Changes } \\
2008 \text { to } 2015\end{array}$ & $\begin{array}{c}\text { Place } \\
\text { guaranteed }\end{array}$ & $\begin{array}{l}\text { Com } \\
\text { puls } \\
\text { ory }\end{array}$ & \multicolumn{6}{|c|}{ Primary } & \multicolumn{3}{|c|}{ Lower secondary } & $\begin{array}{c}\text { One year of } \\
\text { common } \\
\text { curriculum }\end{array}$ \\
\hline Since 2016 & \multicolumn{2}{|c|}{ Place guaranteed } & "0" & \multicolumn{8}{|c|}{ Primary school } & \\
\hline
\end{tabular}

Fig. 5 Changes in the provision of preschool education and compulsory education with the general curriculum (in green)

Overall, when looking at Fig. 5 it is clear that until recently, Poland has consistently followed the path of expanding general education. While before 1999, students had only eight compulsory years of the same general program, those who started education in 2015 have had a right to preschool education from the age of 3 and will be obliged to follow the same general program from the age of 5 until the age of 16 . This makes 11 years of general education material obligatory for all students. Using all the opportunities provided from the age of 3, students will benefit from 13 years of general education rather than the 8 available in the 1990s. It is also worth noting that compulsory education in Poland ends at the age of 18, so all students are also required to continue education until this age.

The 1999 reform introduced external national examinations. The first exams were launched in 2002 and monitored student outcomes at the end of every stage of education (they were conducted after the 6th, 9th, and 12th/13th grades; since the abolition of the lower secondary schools they are now conducted at the end of primary and secondary school). The exams are standardized, so all students answer the same questions, and their results are evaluated centrally to assure fair and comparable judgments. Individual results are available to all students and teachers. The results at the school level are also available to the public. Based on the exam results, the so-called value-added measures of student progress in the lower and upper secondary schools were developed and are now publicly available. The external examination system creates incentives for the improvement of teaching quality. It is quite difficult to punish or reward teachers for the exam results, as they are not linked to individual teachers but to schools only. On the other hand, the results are publicly available, which creates social and political pressure to achieve good outcomes at the school level. The results are also important for lower and upper secondary students as they decide whether students will get to better secondary or tertiary programmes.

Altogether, the external assessments of learning outcomes and the large degree of autonomy enjoyed by Polish schools in terms of teaching seem to provide the right mix of freedom and external monitoring. The market for textbooks was already established in the 1990s but was regulated by the Ministry. School autonomy was extended in 1999 by allowing teachers to decide themselves which textbooks and 
teaching methods to use. The reform also introduced a new system of teacher professional attainment with four levels. The system created incentives to participate in professional development and was also used to increase teacher salaries, as every level comes with better remuneration.

Finally, the 1999 reform changed the governance and financing system. This was further decentralized, with the ownership of schools transferred to local governments, and a new per-student formula to distribute resources was introduced. The reform introduced proper incentives for the rationalization of school networks, which helped schools survive the substantial demographic decline that started in the 1990s. It also increased overall efficiency, as local governments were better at managing schools and their finances than the central government agencies. Currently, local governments are partly responsible for financing education, although most of the funds are still transferred from the central budget, and teachers' salaries are still in large part regulated centrally.

\subsection{Outcomes of the 1999 Reform}

We have already discussed large improvements in student achievement in Poland, as documented by PISA performance trends (see Figs. 3 and 4). More in-depth studies suggest that these improvements are associated mainly with the extension of comprehensive education by one year, which benefited mostly the former basic vocational students and to lesser degree students in vocational secondary education. We will now review the results of an analysis of PISA results that shows large benefits for low-achieving students. Other studies include research using labour market data that follows the cohorts affected and unaffected by the reform. We briefly discuss the results of these studies at the end of this section.

The variations created by the policy change of 1999 can be used to see how the reform affected the reading skills of 15-year-olds. Jakubowski et al. (2016) used a difference-in-differences model that compares the change in test scores of the likely vocational school students who were able to study the general academic curriculum because of the reform. The group of "likely vocational students" is constructed, using the propensity score matching method, by comparing 2003 comprehensive school students with similar characteristics (e.g., gender, socio-economic background) to students who were in vocational schools in 2000. This quasi-experimental approach attempts to show a causal link between the reform and student outcomes, mainly for those who without the reform would likely go to vocational schools directly after primary education.

Table 1 presents the actual results from the PISA 2000, 2003, and 2006 studies and counterfactual averages constructed from samples of matched students. The overall achievement of Polish students increased significantly between 2000 and 2003, with additional improvement between 2003 and 2006. The most interesting question is, however, whether the reform affected students in general secondary, vocational secondary, and basic vocational schools similarly. 
Table 1 Factual and counterfactual scores of students in different upper secondary tracks

\begin{tabular}{l|l|l|l|l|l}
\hline $\begin{array}{l}\text { Reading } \\
\text { achievement }\end{array}$ & $\begin{array}{l}\text { PISA 2000 } \\
\text { factual } \\
\text { weighted } \\
\text { score }\end{array}$ & $\begin{array}{l}\text { PISA 2003 } \\
\text { factual } \\
\text { weighted } \\
\text { score }\end{array}$ & $\begin{array}{l}\text { PISA 2003 } \\
\text { matched } \\
\text { counterfactual } \\
\text { score }\end{array}$ & $\begin{array}{l}\text { PISA 2006 } \\
\text { factual } \\
\text { weighted } \\
\text { mean score }\end{array}$ & $\begin{array}{l}\text { PISA 2006 } \\
\text { matched } \\
\text { counterfactual } \\
\text { score }\end{array}$ \\
\hline All schools & 479.1 & 496.6 & 483.1 & 507.6 & 504.8 \\
\hline $\begin{array}{l}\text { Basic } \\
\text { vocational }\end{array}$ & 357.6 & - & 453.3 & - & 473.5 \\
\hline $\begin{array}{l}\text { Vocational } \\
\text { secondary }\end{array}$ & 478.4 & - & 478.5 & - & 498.2 \\
\hline $\begin{array}{l}\text { General } \\
\text { secondary }\end{array}$ & 543.4 & - & 516.4 & - & 532.0 \\
\hline
\end{tabular}

Source Jakubowski et al. (2016)

Table 2 compares the score improvement among 2003 and 2006 15-year-olds likely to have gone to different types of older secondary school in 2000. In other words, these estimates assess trends in performance for all students and across groups of students who, without the reform, would be in different secondary tracks. Again, there is an overall improvement in average performance among 15-year-olds in Poland. The score improvement for all students is remarkable, around 26 points from 2000 to 2006. Crucial estimates concern the hypothetical performance improvement from 2000 in different tracks. Performance improvement for potential students of former basic vocational schools is simulated to be slightly below 100 points from 2000 to 2003 and 116 points from 2000 to 2006. This is more than one standard deviation of PISA scores in OECD countries, which is a dramatic improvement. These estimates are statistically significant, supporting the hypothesis that 15 -yearold students who, without the reform, would have been placed in vocational tracks benefited greatly from the reform. However, the benefits for students in other tracks are not so evident. Students in vocational secondary schools have similar scores in 2003 and improved scores-by 20 points-in 2006. Students in the general track would potentially have lower scores in 2003 and similar performance in 2006.

Table 2 Propensity-score matching estimates of score change for students in different upper secondary school tracks

\begin{tabular}{l|l|l}
\hline $\begin{array}{l}\text { Reading } \\
\text { achievement }\end{array}$ & $\begin{array}{l}\text { Score change: PISA } \\
\text { 2003_PISA 2000 }\end{array}$ & $\begin{array}{l}\text { Score change: PISA } \\
\text { 2006-PISA 2000 }\end{array}$ \\
\hline All schools & 3.9 & 25.6 \\
& $(5.2)$ & $(5.1)$ \\
\hline Basic & 95.6 & 115.9 \\
vocational & $(8.4)$ & $(7.1)$ \\
\hline Vocational & -5.5 & 19.7 \\
secondary & $(7.8)$ & $(7.5)$ \\
\hline General & -27.0 & -11.4 \\
secondary & $(7.6)$ & $(7.0)$ \\
\hline
\end{tabular}

Source Jakubowski et al. (2016). Standard errors in parentheses 
We now turn to additional results from the national study that used PISA instruments to test 16- and 17-year-old students in upper secondary schools. These results show that students in vocational schools perform better after the reform when compared to students from vocational schools before the reform. This suggests that the reform has a lasting influence on their achievement. On the other hand, these additional data show that after finishing their general education, these students do not gain much more in vocational education in terms of general skills like reading or mathematics.

These findings were confirmed by studies that followed the cohorts of students on the labour market. These studies use a research design that allows for the estimation of the causal impact of the reform, mainly the extension of general education and the labour market outcomes. In general, both studies compare earnings or unemployment among former students who were affected and unaffected by the reform due to small differences in birth dates. Drucker and Horn (2016) compared income and employment probability among adults of nearly the same age but who were born in different months and thus benefited from 8 or 9 years of compulsory general education. According to their quasi-experimental analysis, the reform improved income by around $3-4 \%$ and employment probability by $2-3 \%$. The positive outcomes were larger for the lowest-educated workers, which is in line with the findings from PISA. Using different datasets and focusing on people who finished basic vocational education, Liwiński (2018) found positive labour market effects of the 1999 reform for former male students.

\subsection{The Second Wave of Reforms-Curriculum and Evaluation Reforms from (2008 and 2009)}

The 1999 reform established, as we have seen, the foundations for a modern education system; however, the curriculum was still too prescriptive, focusing on what teachers should teach rather than what knowledge and skills students should acquire. Rapid changes in Polish education, economy, and society called for its modernization. The results of the OECD PISA study were also used to motivate the reform, as until 2012, they showed that Polish students performed relatively worse in analytical or reasoning tasks. The reform started in 2007 with a consultation process, including all major stakeholders in the system. After one-year-long discussions, a new curriculum was passed in 2008. It was implemented gradually, with the last changes affecting upper secondary schools several years later.

The new curriculum was developed according to these principles:

- Describe the expected learning outcomes for each stage of education,

- Indicate the main objectives of teaching for each school subject,

- Define the requirements of central assessments,

- Constitute a coherent part of the Polish Qualifications Framework. 
As one of the authors of the reform writes (Marciniak 2015): "The curriculum has two layers. The basic layer comprises 3-5 general requirements for each subject, which defines the main objective for teaching a given subject at a given education level. For example, for mathematics at lower secondary school the general requirements include mathematical modelling, strategic thinking, and mathematical reasoning and argumentation. This implies that the primary goal of the teaching process as a whole should be oriented towards developing these skills. The second layer consists of detailed requirements, describing the specific knowledge and skills to be mastered by students, e.g., " a student can solve a system of two linear equations." However, these particular requirements serve only as a tool in achieving more general aims, as defined by the general requirements."

The new curriculum has strengthened teacher autonomy but also the responsibility for the learning process, as it defines learning outcomes only and in a relatively broad manner. It emphasized the general goals of teaching in each subject, leaving a lot of space for teachers in terms of developing their programs and the choice of resources to use. The national exams were aligned with the new curriculum and attempt to focus more on reasoning than on fact-checking.

In fact, the improvement of Polish students between the PISA 2009 and PISA 2012 studies was mostly driven by better responses to items measuring more complex, analytical thinking, at least in mathematics. The reform also emphasized crosscurricular skills and teamwork, while those elements are still only partly implemented in classroom practice.

The new curriculum introduced two substantial changes in upper secondary schools. Firstly, some subjects were combined into interdisciplinary blocks for students who specialize in other subjects (e.g., students focusing on physics would have history classes combined into social science blocks). This change was misinterpreted and criticized as limiting the teaching of history, while, in fact, the number of hours devoted to history teaching was the same but organized differently. The second was the obligation to cover at least an equivalent of one year of the general curriculum in basic vocational schools. While this change was in line with the idea of extending the coverage of general education to all students, in practice, it did not bring the expected results due to the limited teaching capacity in basic vocational schools, low motivation of students, and probably also a too-short period of implementation. In general, these two changes were the most criticized and problematic and were reversed with the new curriculum introduced in 2016.

Another large change was the introduction of school evaluations that replaced the old inspection-type system (see Mazurkiewicz et al. 2014). When developing this system, researchers and decision-makers reviewed several school evaluation systems in other countries, mostly looking at those that performed well in international assessments, e.g., Finland, Scotland, and the Netherlands. Thus, this development was motivated by international comparisons, while the final system decided upon was unique, incorporating only some ideas from other countries.

Prior to the reform, inspections focused on checking administrative and legal issues, sometimes pretending to assess teaching quality but without any substantial investigations involved. The new system was evidence-driven, with the aim of 
providing feedback that could help to improve teaching quality. From 2009 the school evaluation system was incorporated into the supervisory structures as a basic method of pedagogical supervision and separated from administrative or legal control. The evaluation was based on a set of requirements that should be addressed by each educational facility. The requirements covered a broad set of activities like delivery of the core curriculum, the development of selected student attitudes and social skills, cooperation with parents, organization of work, and analysis of examination results.

Importantly, the whole process is transparent and inclusive. The evaluation reports are published and discussed with school staff and stakeholders. The goal is to encourage open evidence-based reflection about teaching and school organization. While the system has been modified several times already, and the current administration is not highly supportive of it, it has become an important part of the education system. Currently, both school evaluations and examination results are publicly available at the school level.

\subsection{Early Education Reform}

International comparisons clearly pointed to one key deficiency of the Polish education system - the relatively low participation rate in preschool education and the later starting of school education (and the later finishing of tertiary education as a result). Changes began in 2007, with support for preschool education from the European Structural Funds, which was followed in 2009 with a government guarantee for places for 5-year-olds in preschool education. This was then replaced in 2011 with compulsory preschool education for children at this age. The plan also assumed a shift in compulsory primary school arrangements, with the starting age changing from 7 to 6 in 2012. However, the latter change was postponed and never fully implemented due to protests and the change of government.

Before the reform, Poland had one of the lowest preschool participation rates in Europe. Figure 6 shows that in 2000 around 58.3\% of Polish children participated in preschool education before starting primary school, which can be compared to $85.5 \%$ across the 28 EU countries. This participation rate started to increase slowly until 2007 and then more rapidly, mostly thanks to large developments in rural areas. In fact, the preschool participation rate of 3- to 5-year-olds in rural areas was below $25 \%$ before 2007. With the help of European Structural Funds and later the support of the central government, the rural local governments could fund new places for preschool education, and in 2014 the participation of 3- to 5-year-olds in preschool education increased to $70 \%$ in rural areas.

Overall, Poland almost closed the gap in preschool participation in 2016, mainly due to regulations making preschool compulsory and thanks to additional support for local governments. In 2013, a law was passed that lowered the costs of preschool education for families thanks to grants from the central budget. The government also introduced a guarantee of preschool places for 3- and 4-year-olds that was financed by the central budget and introduced gradually. A recent small decline in preschool 


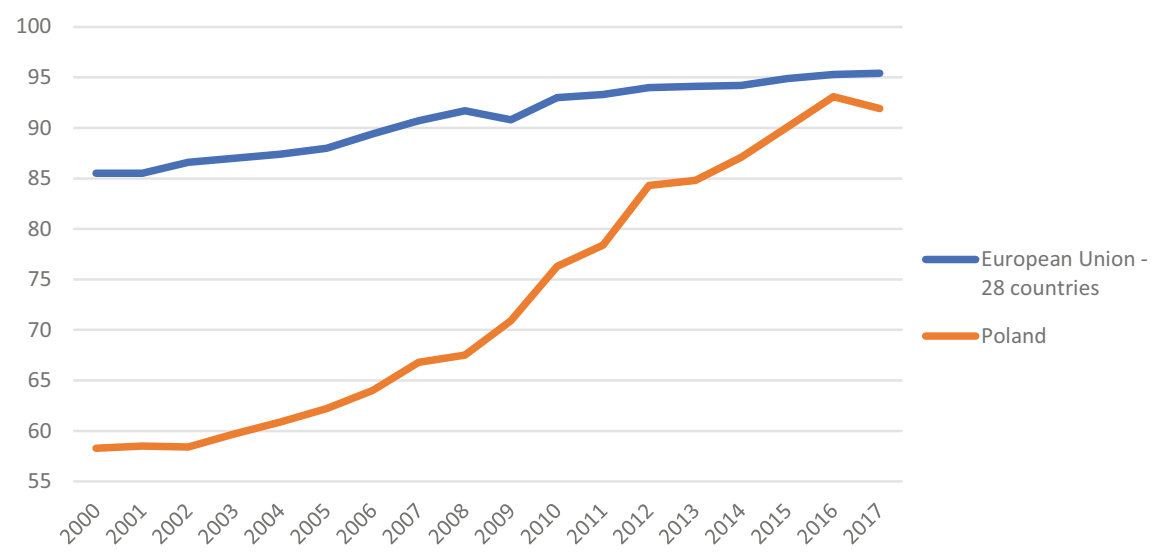

Fig. 6 Participation in preschool education-Poland and EU average. Source Eurostat, \% of the age group between 4-years-old and the starting age of compulsory education. Indicator SDG_04_30 retrieved at 8 th of January 2020

enrolment is the effect of the current government's abolition of compulsory preschool for 5-year-olds, but still, the participation rates are now close to the EU average and much larger when compared to 2007 when the reform started.

One can see this reform of early education as the final step in building a comprehensive education system in Poland. Thanks to the reforms, all students now have access to comprehensive education from the age of 3 until the age of 15, with additional, obligatory one-year comprehensive material that needs to be covered in all types of upper secondary schools. Thus, for the Polish students who want to fully benefit from the system, free comprehensive education can now last for 13 years.

\section{Evidence, Public Sentiment, Politics, and Top-Down Reforms}

The reforms implemented between 1999 and 2013 extended compulsory general education, increased preschool participation and modernized the Polish school system. International assessments like PISA, but also PIAAC, TIMSS, and PIRLS, demonstrate how successful these changes were. The latest PISA results show the cumulative effect of improved quality at the primary and lower secondary levels, with Polish students ranking among the top performers in Europe in all subjects. Mathematics was typically the weakest domain for Polish students, but it has been heavily reformed in recent years. Now, in Europe Polish 15-year-olds are outperformed only by Estonians and scored better than young Finns, whose school system is often celebrated in Poland as of higher quality. The evidence shows large gains for low-achieving students and a large decline in between-schools differences after the 1999 reform. These positive outcomes are also confirmed by labour market studies 
showing that the extension of compulsory general education can be directly linked to earnings and a lower probability of unemployment, especially for people with vocational degrees. The improvements after 2009 were larger for higher-achieving students. We still need to wait for more in-depth research analysing the impact of the reforms in this period.

The overwhelming evidence in support of the 1999 reform was not widely discussed until the current government decided to change the system. Large protests against the reversal of this reform, which were driven by teacher trade unions, but also supported by groups of parents, researchers, and education experts, did change the views of some people. Surveys of public opinion showed that positive or negative views were closely related to political preferences (for example, see CBOS 2018). The reversal of the reforms was positively viewed by voters of the current ruling party and negatively by those who support opposition parties. Also, the older generations viewed more positively the system inherited from the communist times, while younger people, including those who were actually educated in the lower secondary schools, would as majority support keeping the system as introduced in 1999.

Clearly, the politics of this reform are not related to evidence but have more to do with sentiment and political views. The issue of education reforms was heavily politicized. At the same time, it did not matter that the current party, which reversed these reforms, was among the first to support them some time ago as the opposition party. What matters for the opinion of most people who are not directly involved in education is the current political battle and not the school reform itself.

At the same time, while politics and sentiment seem to be key factors in understanding the support for the reversal of the reforms, they cannot explain everything. Among people who were against the reversal of the 1999 reform, many share negative opinions about its implementation in 1999, have negative views of the current education system, and did not support the early education reforms, especially the lowering of the starting school age.

First, the perception of the 1999 reform is generally negative, and even for people who can recognize successful outcomes, the popular notion is that this reform was chaotic and implemented by force. The implementation of the reform was partly motivated by a wish to dismantle the remaining elements of the education system inherited from the communist times. The reform was introduced in the package of four large reforms (pension reform, health reform, administration reform), which added up to an enormous burden during the implementation. Overall, the reform was difficult for three reasons: it was extremely ambitious and had a list of components that would be sufficient for several reforms (change of school structure, decentralization, change of financing, change of curriculum and textbooks); political opposition; and additional issues caused by the almost-parallel implementation of the other three reforms. Teachers and parents were overwhelmed by the number of changes introduced. In effect, although in the beginning, public opinion expressed more positive views on the reform, the negative opinions increased soon after the implementation and are still present nowadays. While many teachers saw the reform as a chance to improve their situation, they were also afraid of the changes and expressed negative views on the implementation. Negative views on the reform were also amplified 
by negative receptions of the other three reforms, which, except for administrative reform, were highly unpopular and have also been reversed recently to a large degree.

It is doubtful, however, that these needed reforms could have been implemented in a less controversial way or with a longer period of consultation and consensusforming. The government collapsed shortly after the implementation of the education reform, and some changes were quickly reversed by the succeeding governments (for example, an obligatory standardized mathematics exam at the end of upper secondary school was postponed for nearly ten years). Also, important changes have remained even after the recent reform reversal, including not only system-level solutions but also the attitudes of students and teachers. Attempts to re-centralize education are difficult to imagine now, even if the current government tries to limit the autonomy of local governments and schools. Despite difficulties in the beginning, local governments managed educational facilities more efficiently, while teachers used the freedom given by increased autonomy to improve learning outcomes. Fewer students are in basic vocational education now, and enrolment in tertiary education institutions is still high.

Second, the negative view of the reforms and the current education system might be related to the limited role played by parents. Reformers tried to implement regulations giving parents and students more saying in the management of schools, but attempts to formalize the role or set up parents' councils in schools did not succeed, and they still play a mainly advisory role. Similarly, students and other stakeholders, e.g., local NGOs or employers, play limited roles in shaping local schools. This lack of representation of key stakeholders at the local and national levels is often criticized and results in harmful tensions.

Finally, there is criticism of the Polish education system coming from education experts and opinion leaders, which claims it is an old-fashioned system that also does not deal properly with inequality. Many claims about curricula and innovative teaching methods are disputable, as the proposed approaches are rarely new and are often unsupported by research evidence (see Christodoulou 2013, for a discussion of education myths popular in the UK, but also repeated in Poland). The so-called teaching of $21^{\text {st }}$-century skills is disputable, and one can easily say that Polish schools are able to find a good balance between innovations and traditional teaching, securing very good outcomes for most students. The other criticism is related to inequality and is often linked to the discussion of how socio-economic background is related to student performance in PISA. It is true that the overall effect of socio-economic background on achievement has not changed much, but that is mainly due to the fact that large improvements among low-achieving students were accompanied by similarly large improvements among top-achievers. The differences between students of different backgrounds are average or below average in Poland. The expansion of general education and increased support for preschool education are probably the two most effective policies aimed at limiting the impact of socio-economic background on students. The belief that schools can become the big equalizer in a society as divided as Poland can use international assessments to show that the improvements made in Poland are substantial from a relative and not from the absolute perspective. 


\section{Conclusions}

Since 2000 the Polish education system has been reformed several times, with the most recent wave of reforms reversing key changes implemented earlier. The 1999/2000 reform restructured, decentralized, and introduced standardized national examinations. The reforms around 2007/2008 introduced a new core curriculum and school evaluation system. Later preschool and early education were reformed. The most recent changes partly reversed earlier reforms, but it seems that the system follows its dynamic based on substantial teacher and school autonomy.

Student outcomes, as documented by PISA, but also other international assessments, largely improved over the last 20 years. Thanks to the expansion of compulsory general education, Poland managed to narrow differences between schools and to improve the performance of its low-achievers significantly. Second waves of reforms improved the overall quality of the system, with a larger degree of improvement obtaining among top-achieving students and in mathematics.

There are three lessons from the Polish experience with the implementation of the reforms and the recent reversal of most of them. First, the evidence is not sufficient to support and sustain reforms. The Polish success in PISA was not widely known or sufficiently promoted by education experts and leaders. Even the improving results from the other international assessments did not convince the public that the school system performs very well and that Poland is among the top-ranking countries in Europe. This evidence should be discussed more widely, common misconceptions or invalid criticism should be addressed, and a feeling of being proud of the achievements of the school system should be promoted and celebrated. But nothing like this has happened in Poland. Thus, it is not surprising that many people still do not believe the results from PISA are true or that the results of international comparisons are sufficient for them to change their negative views.

Second, it is not sufficient to rely on international assessments and international reports, while it is necessary to develop a reflective culture of policy and practice, which would support continuous research efforts. International assessments do provide reliable benchmark comparisons allowing for the evaluation of the overall outcomes of the education system in each country. However, the most important questions related to policy outcomes need to be addressed using the secondary analysis of international data and national research. Moreover, the results of these analyses need to be more widely disseminated and popularized among education experts, teachers, parents, and policymakers. Too often, the research community and ministries invest a lot into data collection, only to rely later solely on international reports. This is a serious under-utilization of international assessments and limits their impact on education policy and practice.

Third, not all of the changes stemming from 1999 and the later reforms have been reversed, and some of them became a solid foundation for the Polish education system. Maybe the most important changes are in the attitudes of students and teachers. Most families and students believe nowadays that it is possible to achieve a 
tertiary or another diploma that provides better labour market opportunities. Teachers have a feeling of substantial pedagogical autonomy and focus on student outcomes. These and other changes have had a large influence on system outcomes.

\section{References}

Białecki, I., Jakubowski, M., \& Wisniewski, J. (2017). Education policy in Poland: The impact of PISA (and other international studies). European Journal of Education, 52, 167-174.

CBOS, (2018). Ocena systemu edukacji po roku od wprowadzenia reformy. Komunikat z badań 122/2018, Centrum Badania Opinii Społecznej.

Christodoulou, D., (2013). Seven myths about education. Routledge.

Drucker, L. F., \& Horn, D. (2016). Decreased tracking, increased earning: Evidence from the comprehensive Polish educational reform of 1999. Budapest Working Papers on the Labour Market 1602, Institute of Economics, Centre for Economic and Regional Studies, Hungarian Academy of Sciences.

Gajderowicz, T., Grotkowska, G., \& Wincenciak, L. (2012). Premia płacowa z wykształcenia wyższego według grup zawodów. Ekonomista (5).

Jakubowski, M., \& Topinska, I. (2009). The impact of decentralization on education in Poland. In E. Ahmad \& G. Brosio (Eds.), Does decentralization enhance service delivery and poverty reduction? Chapter 9, Edward Elgar Publishing.

Jakubowski, M., Patrinos, H., Porta, E., \& Wiśniewski, J., (2016). The effects of delaying tracking in secondary school: Evidence from the 1999 education reform in Poland. Education Economics, 24(6), 557-572.

Liwiński, J. (2018). The impact of compulsory schooling on earnings. Evidence from the 1999 Education Reform in Poland, No 253, GLO Discussion Paper Series, Global Labor Organization (GLO)

Marciniak, Z. (2015). Reviewing polish education reform in the late 1990s-possible lessons to be learned, The World Bank.

Mazurkiewicz, G., Walczak, B., \& Jewdokimow, M. (2014). Implementation of a New School Supervision System in Poland, OECD Education Working Papers No. 111, OECD Publishing, Paris.

OECD. (2019). PISA 2018 assessment and analytical framework. PISA: OECD Publishing, Paris. Rynko, M. (Ed.). (2013). Umiejętności Polaków - wyniki Międzynarodowego Badania Kompetencji Osób Dorostych (PIAAC). Warszawa: Instytut Badań Edukacyjnych.

Maciej Jakubowski is a policymaker, advisor, and researcher in education and labour market policy. He served as an under-secretary of state (deputy minister) at the Polish Ministry of National Education between 2012 and 2014. In 2014, he established the Evidence Institute in Poland to promote evidence-based policymaking and teaching practice. Before joining the government, he worked in the OECD PISA team in Paris (between 2008 and 2012). He worked as a consultant for the World Bank, UNDP, UNESCO, OECD, and several other governments and international institutions. Mr. Jakubowski holds a Ph.D. degree in economics and MA in sociology from the University of Warsaw where he still works at the Faculty of Economic Sciences. His research focuses on statistical methods for policy evaluation and the development and analysis of student assessments. 
Open Access This chapter is licensed under the terms of the Creative Commons Attribution 4.0 International License (http://creativecommons.org/licenses/by/4.0/), which permits use, sharing, adaptation, distribution and reproduction in any medium or format, as long as you give appropriate credit to the original author(s) and the source, provide a link to the Creative Commons license and indicate if changes were made.

The images or other third party material in this chapter are included in the chapter's Creative Commons license, unless indicated otherwise in a credit line to the material. If material is not included in the chapter's Creative Commons license and your intended use is not permitted by statutory regulation or exceeds the permitted use, you will need to obtain permission directly from the copyright holder.

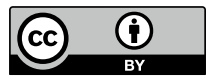

